\title{
Stay-in-Place Formwork of TRC Designed as Shear Reinforcement for Concrete Beams
}

\author{
S. Verbruggen, O. Remy, J. Wastiels, and T. Tysmans \\ Department of Mechanics of Materials and Constructions (MeMC), Faculty of Engineering Sciences, Vrije Universiteit Brussel (VUB), \\ Pleinlaan 2, B-1050 Brussels, Belgium
}

Correspondence should be addressed to S. Verbruggen; svetlana.verbruggen@vub.ac.be

Received 7 December 2012; Revised 26 March 2013; Accepted 28 March 2013

Academic Editor: Roham Rafiee

Copyright (C) 2013 S. Verbruggen et al. This is an open access article distributed under the Creative Commons Attribution License, which permits unrestricted use, distribution, and reproduction in any medium, provided the original work is properly cited.

\begin{abstract}
In order to reduce on-site building time, the construction industry shows an increasing interest in stay-in-place formwork with a reinforcement function after concrete hardening, such as CFRP formwork confinement for columns. The current combined systems however do not answer the demand of the building industry for a material system that is both lightweight and fire safe. High performance textile reinforced cement (TRC) composites can address this need. They can be particularly interesting for the shear reinforcement of concrete beams. This paper describes a preliminary analysis and feasibility study on structural stay-in-place formwork made of TRC. Comparative bending experiments demonstrate that a fully steel reinforced beam and an equivalent beam with shear reinforcement in TRC formwork show similar yielding behaviour, indicating that the TRC shear reinforcement system actually works. Moreover, the cracking moment of the concrete was more or less doubled, resulting in a much lower deflection in serviceability limit state than calculated. Digital image correlation measurements show that the latter is due to the crack bridging capacity of the external TRC shear reinforcement.
\end{abstract}

\section{Introduction}

Structural stay-in-place formwork is already widely used for some types of concrete elements like floor slabs. But for other types, like concrete beams, few commercial systems are available. Generally the existing systems are made out of timber, steel, or fibre reinforced polymers (FRP) [1, 2]. All of them combine on the one hand the advantages of prefabrication like speed, accuracy, controlled surface quality, and finish and on the other hand the advantages of in situ casting like economy and continuity. Another big advantage is the reduction of manual labour and thus of salary cost, since there is no tying of the steel stirrups and no assembly and dismantling of the formwork. This formwork can also be seen as a protection of the concrete from the environment, which may lead to considerations concerning the necessary concrete cover when steel reinforcement is used. Nevertheless there are some drawbacks of the current systems mainly related to the used materials, such as the durability of timber, the corrosion sensitivity of steel, and the fire resistance of FRP. The above mentioned drawbacks can be solved by the use of textile reinforced cement (TRC), which makes it possible to create a lightweight, durable, and fire safe structural stay-inplace formwork system.

Some studies have already investigated the use of TRC as an externally bonded reinforcement for concrete beams, or as a formwork [3, 4], or as a strengthening and repair technique [5-9]. Particularly for the formwork applications the main difference between the existing studies and this research is the high fibre content (more than 20\%), as will be discussed in Section 2. As a result of this high fibre amount, and thus high tensile capacity of the material, lighter and thinner-walled stay-in-place formwork solutions can be designed. Moreover, the very small crack opening of less than $10 \mu \mathrm{m}$, invisible for the naked eye, may constitute an additional advantage in reducing the necessary concrete cover.

Considering the need for a lightweight, durable, and fire safe combination of formwork and reinforcement for concrete beams, and considering the important differences with the existing state of the art, it is useful to perform a preliminary analysis and feasibility study on structural stay-in-place formwork made of TRC. This paper evaluates 
the feasibility of TRC formwork as shear reinforcement. Four point bending tests, with third point loading, are performed on (i) a fully steel reinforced referential beam, with longitudinal and stirrup reinforcement, and (ii) a composite beam with longitudinal steel reinforcement and TRC stay-inplace formwork as shear reinforcement. The experiments are monitored with digital image correlation to follow the crack pattern evolution.

\section{Textile Reinforced Cements}

Cementitious materials are stiff and strong materials, but they are characterized by a low tensile strength and a brittle behaviour. Therefore these materials need to be reinforced with traditional steel reinforcement or, alternatively, with fibres. Until now most studies concerning fibre reinforcement for concrete concentrated on discontinuous fibre structures, which can increase significantly the ductility but hardly or not the tensile strength [10]. A ductile cement matrix composite with an increased tensile strength can be obtained by using a dense and continuous fibre structure such as fibre textiles, leading to a textile reinforced cement (TRC). The production techniques as well as the mechanical properties of TRC are closer to the ones of polymer matrix composites than to those of more common cement composites with discontinuous fibre structures: with techniques like tape winding, pultrusion, or calendaring it is possible to achieve cement composites with a high fibre content (more than $20 \%$ in volume [11]) and to control the alignment of the fibres. This leads to a stable crack development and a strain hardening behaviour with a significant postcracking stiffness and a high tensile strength. The small diameter of the fibres results moreover in a very fine crack pattern [12].

Cost effective E-glass fibres are often used in the composites industry. An important drawback however of these fibres in combination with a cementitious matrix is the reduction of the performance of the fibres with time, due to the alkaline environment of an ordinary concrete or mortar [13] and to portlandite deposition. In order to avoid fibre degradation the Vrije Universiteit Brussel developed an inorganic phosphate cement (IPC) [14], which is acidic in fresh state but $\mathrm{pH}$ neutral after hardening. The time of the acidic phase is sufficiently short not to degrade the properties of the glass fibres. Its relatively small grain size (between 10 and $100 \mu \mathrm{m}$ ) moreover enables to impregnate dense textiles up to high fibre volume fractions (more than $20 \%$ in volume [11]). As a result, a durable cementitious composite with high tensile (up to $60 \mathrm{MPa}$ for IPC reinforced with randomly oriented glass fibre textiles) and compressive ( $80 \mathrm{MPa}$ ) capacities and which is heat- and fire-resistant (highest European class A1) is created, which makes it appropriate for structural applications.

Under compressive stress states, the constitutive behaviour of glass fibre textile reinforced IPC can be assumed to be linear elastic until failure of the matrix ( $80 \mathrm{MPa}[15])$. Under tensile stresses, on the contrary, it shows a complex and nonlinear stress-strain evolution (Figure 1).

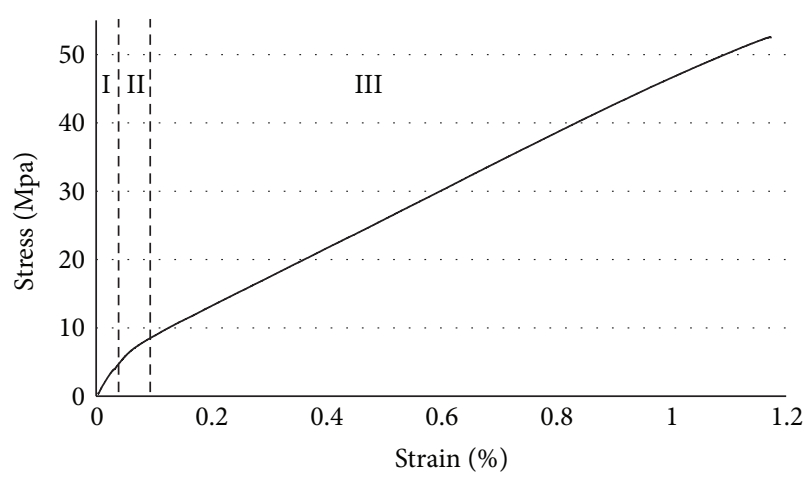

FIGURE 1: The nonlinear tensile stress-strain behaviour of IPC reinforced with glass fibres randomly oriented in a plane mat (HPFRCC IPC).

Three stages (I, II, and III in Figure 1) can be distinguished in the TRC IPC tensile behaviour. The initial behaviour in stage I is linear elastic, and fibres and matrix can be assumed to work perfectly together. Since the tensile failure strain of the matrix is low, cracks will occur at low stresses and strains. When sufficient fibres are present to take over the load at the crack location, multiple cracking will occur (stage II). It can be noticed from Figure 1 that crack formation is a nonlinear and gradual process. Once the matrix is fully cracked, only the fibres will contribute to the tensile strength and stiffness of the material (stage III), until the fibres fail.

Glass fibre textile reinforced IPC can be classified as a high performance fibre reinforced cement composite (HPFRCC), as it fulfils the requirements specified in [16]. The main requirements imply multiple cracking behaviour with crack width control, strain hardening behavior, and a high tensile strength. Following this classification this material will be referred to as HPFRCC IPC.

\section{Specimen Design}

In order to evaluate the feasibility of structural stay-in-place formwork in HPFRCC IPC, two different types of beams are designed and tested:

(i) a fully steel reinforced referential beam, with longitudinal and stirrup reinforcement;

(ii) a composite beam with longitudinal steel reinforcement and HPFRCC IPC stay-in-place formwork as shear reinforcement.

The first beam type will be cast using conventional formwork; hence only the permanent state has to be calculated. For the second beam type, the formwork will be used as shear reinforcement, so it has to resist the final loads (permanent state) as well as the temporary ones (temporary state) during the construction of the concrete element. As this study focuses on the feasibility of the HPFRCC IPC shear reinforcement in the permanent state, the temporary state will not be taken into account for the design of the beam.

The following choices were made for the model beams, considering the limitations of the laboratory setup. The beams 


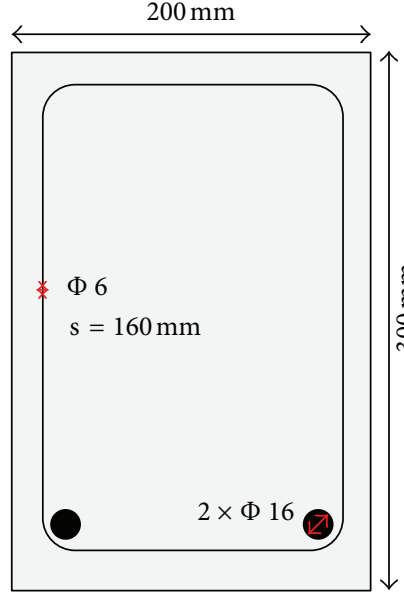

(a)

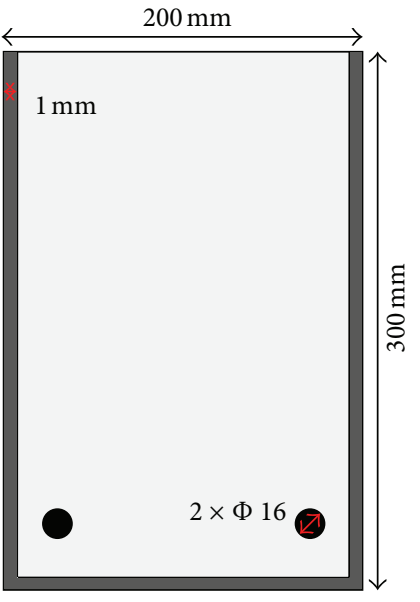

(b)

FIGURE 2: (a) Fully steel reinforced reference beam; (b) composite beam with longitudinal steel reinforcement and HPFRCC IPC formwork as shear reinforcement.

have a width of $0,2 \mathrm{~m}$, a height of $0,3 \mathrm{~m}$, and a span of $2,3 \mathrm{~m}$. The longitudinal steel reinforcement consists of 2 bars with a diameter of $16 \mathrm{~mm}$. The diameter of the stirrups for the reference beam is chosen to be $6 \mathrm{~mm}$ (Figure 2(a)). The beams will be tested under four-point bending with third-point loading. With these assumptions the maximum bending moment in the ultimate limit state is calculated using Eurocode 2 [17]. Then, once the total maximum load corresponding to this bending moment is known, the necessary amount of stirrup reinforcement for the reference beam is calculated. The amount of HPFRCC IPC shear reinforcement is calculated such that the composite beam is capable of bearing the same shear loads in the permanent state as the reference beam [18].

For the reference beam these calculations result in a maximum load of $133,5 \mathrm{kN}$, with stirrups placed every $160 \mathrm{~mm}$ in the shear zones of the beam.

In the composite beam (Figure 2(b)), identical longitudinal reinforcement is placed but the shear reinforcement is $U$-shaped and made of HPFRCC IPC reinforced with chopped strand glass fibre mats (randomly oriented in the plane). This shear reinforcement is designed with a constant thickness along the length of the beam and acts as stay-inplace formwork.

Direct tensile and shear tests performed on specimens of concrete cast upon HPFRCC IPC laminates show that failure never occurs in the interface between both materials, but either in the laitance layer of the concrete or interlaminar between the glass fibre mat layers in the HPFRCC IPC. Hence, a perfect initial bond between both materials can be assumed for the design [18].

As the shear reinforcement of the composite beam is an external reinforcement, the necessary amount is calculated in analogy with the procedures described in the fib bulletin 14 for externally bonded FRP reinforcement for RC structures [19]. The maximum load, dimensions, and longitudinal reinforcement are taken identical to these of the reference beam. The material characteristics are the ones that will be discussed in Section 4.2. It is assumed that cracks occur under an angle of $45^{\circ}$ with respect to the longitudinal axis of the beam.

The approach of the FIB 14 uses a reduced value of the ultimate strain of the external reinforcement, the effective strain $\varepsilon_{\mathrm{fe}}$, to take into account that the principal stress direction $\left( \pm 45^{\circ}\right.$ with respect to the longitudinal axis of the beam) is not the same as the fibre orientation (in most cases $90^{\circ}$ with respect to the longitudinal axis of the beam, as unidirectional fibres are used perpendicular to the length axis of the beam). The shear reinforcement in this study is made of IPC reinforced with chopped strand glass fibre mats, where the fibres are randomly oriented in the plane. This random fibre orientation results in an in-plane isotropic elastic modulus, so no correction of the ultimate strain is needed, but a fibre efficiency has to be introduced. This efficiency is taken equal to $1 / 3$, which is based on the value theretofore in stage I (uncracked) and on the lowest value theretofore in stage III (postcracking) for unconstrained fibres, as described in [20]. With these assumptions the calculation equals the one for steel stirrups described in Eurocode 2 [17]. The needed thickness of the HPFRCC IPC to withstand the same maximum load as the reference beam is only $1,0 \mathrm{~mm}$, which corresponds to 2 glass fibre mat layers (see Figure 2(b)).

As a comparison, and following the calculation method described in the fib bulletin 14 for externally bonded FRP reinforcement for RC structures [19], only one layer of continuous unidirectional carbon fibre fabric (like, e.g., PC Carbocomp with a mass of $225 \mathrm{~g} / \mathrm{m}^{2}$ [21]) is needed to fulfil the same demands. In this calculation an ultimate strength of $4000 \mathrm{MPa}$, an ultimate strain of $1,60 \%$, a fabric thickness of $0,125 \mathrm{~mm}$, and a fibre orientation perpendicular to the longitudinal direction of the concrete beam were assumed. After in situ impregnation of the fabric this would result in a total FRP thickness of about $0,5 \mathrm{~mm}$.

For verification of the serviceability limit state, stress limitation, deflection and crack control (by a minimum reinforcement area and a maximum distance between the 


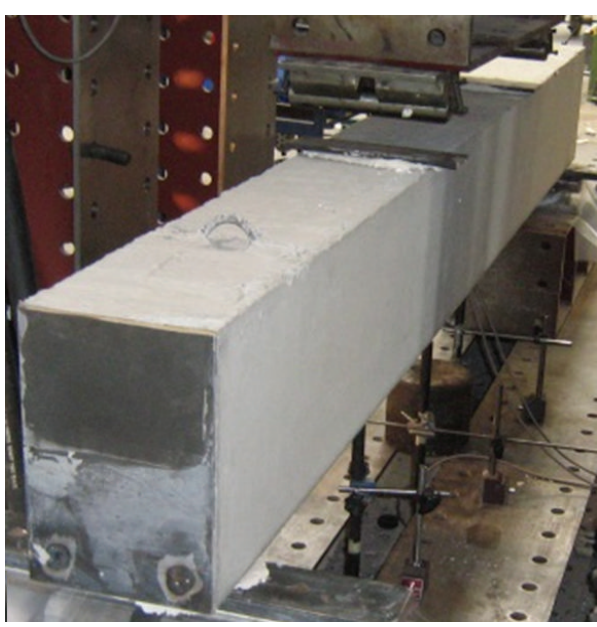

(a)

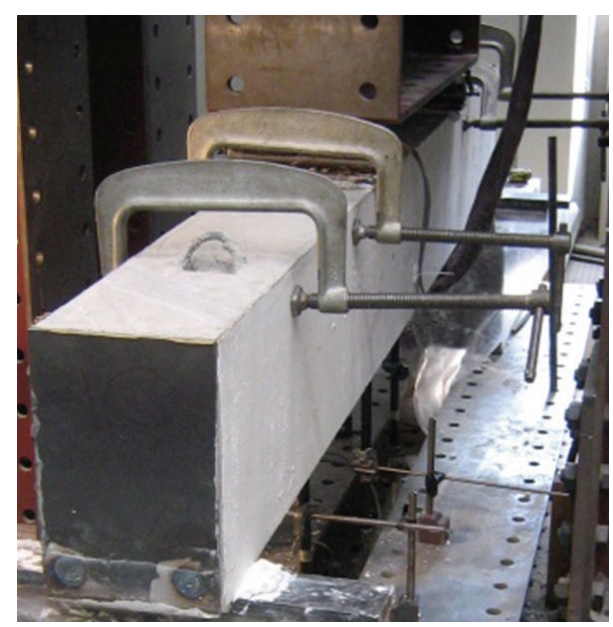

(b)

Figure 3: The test set-up for the reference beam (a) and the composite beam (b).

reinforcement bars) are taken into account. None of these serviceability limit states poses a problem, nor for the reference beam, nor for the composite beam [18].

\section{Experimental Program}

4.1. Test Set-Up. The referential beam and the HPFRCC IPC shear reinforced beam are compared in their load bearing behaviour by a four-point bending test with thirdpoint loading. The loading is displacement controlled with a displacement rate of $0,2 \mathrm{~mm} / \mathrm{min}$, using a servohydraulic actuator (Instron) with a capacity of $500 \mathrm{kN}$. The test set-up is illustrated in Figure 3.

The upper part of the external HPFRCC IPC shear reinforcement is compressed. To avoid plate bucking of this shear reinforcement and to make the yielding of the longitudinal steel reinforcement possible, 4 clamps are applied over the sides of the beam.

The crack evolution of the composite beam is monitored by measuring the relative displacements of the shear reinforcement surface with digital image correlation (DIC) [22]. The load versus deflection curves are obtained using an LVDT placed below the beams in the centre of the span. These experimental curves are compared with theoretical predictions that are obtained using Eurocode 2 [17] and fib bulletin 14 [19]. For this comparison the mean experimental material characteristics, as discussed in Section 4.2, are used. No characteristic values, reduction coefficients, or safety factors on the loads are applied.

\subsection{Used Materials}

4.2.1. HPFRCC IPC. The matrix material IPC is mixed in the mass proportions of

(i) 1 vubonite liquid component,

(ii) 0,82 high performance vubonite powder.
TABLE 1: Material characteristics of HPFRCC IPC.

\begin{tabular}{lc}
\hline Interlaminar shear strength (MPa) & 4,4 \\
Tensile strength (MPa) & 50,0 \\
Ultimate strain (\%) & 1,2 \\
Young's modulus stage I (GPa) & 18,0 \\
Young's modulus stage III (GPa) & 4,0 \\
\hline
\end{tabular}

The randomly in plane oriented fibre textiles used for the shear reinforcement are chopped strand mats Vetrotex M5, with a surface density of $300 \mathrm{~g} / \mathrm{m}^{2}$. To avoid problems with the temporary state, it is chosen to use 4 fibre layers instead of the calculated 2 layers, resulting in a thickness of $2 \mathrm{~mm}$ and a fibre volume fraction of around 12\%. This raise in shear reinforcement will result in differences in the calculated behaviour, as will be discussed in Section 5 and in Section 6. After impregnation, the wetted fibre mats are placed in a wooden formwork to obtain their final $U$-shape. A plastic sheet is put over the laminates to avoid evaporation of the liquid component, and plates are clamped against the upstanding sides so that they experience a uniform pressure and compaction.

The material characteristics of the produced HPFRCC IPC shear reinforcement are described in Table 1 . The values are the mean values of 3 test specimens for the interlaminar shear strength and 2 specimens for the other characteristics. The interlaminar shear strength was measured following the method described in the ASTM D2344 standard [23].

4.2.2. Concrete. The concrete used for the beams was mixed in the following mass proportions:

(i) $375 \mathrm{~kg}$ Portland cement CEM I, 32.5R

(ii) $210 \mathrm{~L}$ water

(iii) $690 \mathrm{~kg}$ sand $0 / 2$

(iv) $1125 \mathrm{~kg}$ gravel 7/14

(v) $1.5 \mathrm{~kg}$ air entraining agent. 
TABLE 2: Material characteristics of concrete.

\begin{tabular}{lcc}
\hline & $\begin{array}{c}\text { Fully steel } \\
\text { reinforced beam }\end{array}$ & $\begin{array}{c}\text { Composite steel } \\
\text { HPFRCC IPC beam }\end{array}$ \\
\hline $\begin{array}{l}\text { Compressive strength } \\
\text { (MPa) }\end{array}$ & 35,2 & 33,2 \\
Young's modulus (GPa) & 31,7 & 31,7 \\
Modulus of rupture (MPa) & 2,8 & 2,3 \\
\hline
\end{tabular}

TABLE 3: Material characteristics of steel reinforcement.

\begin{tabular}{ll}
\hline Yield stress $(\mathrm{MPa})$ & 500,7 \\
Young modulus $(\mathrm{GPa})$ & 203,6 \\
\hline
\end{tabular}

The referential beam and the HPFRCC IPC shear reinforced beam were manufactured with concrete coming from 2 different batches. The corresponding concrete material characteristics are described in Table 2. The values are the mean values of 3 test specimens for the compressive strength, 2 for the modulus of rupture, and 1 for Young's modulus. These material characteristics are experimentally determined after 28 days.

4.2.3. Steel Reinforcement. The traditional steel reinforcement consists of ribbed bars made of S500 steel, of which the material characteristics are described in Table 3. The values are the mean values of 2 test specimens.

The reinforcement bars are welded to steel plates at the end of the beams (see Figure 3); this eases the positioning and placing of the rebars and eliminates potential problems with the anchoring length of the reinforcement bars. For the referential beam the stirrups were welded to the longitudinal bars as well.

\section{Results and Discussion}

5.1. Load-Deflection Curves. In the following experimental analysis, the load bearing behaviour of the referential beam and the HPFRCC IPC shear reinforced beam are compared to each other as well as to theoretical predictions. The beams are tested in a four-point bending test with third-point loading. In Figures 4 and 5 the dotted line represents the analytically calculated load-deflection curve of these beams, while the full line is the experimental curve. The analytical calculation is based on Eurocode 2 prescriptions (chapter "7.4.3 Checking deflections by calculation", formulas 7.18 and 7.19) [17]. No creep or shrinkage factors are taken into account and the load is assumed to be short term and not cyclic.

5.1.1. Fully Steel Reinforced Beam. The experimental loaddeflection curve of the fully steel reinforced beam (Figure 4) initially shows a linear elastic part $(0-16 \mathrm{kN})$, after which the curve bends in a second part $(16 \mathrm{kN}-36 \mathrm{kN})$, where the concrete cracks. After this concrete cracking, the beam behaves linearly again $(36 \mathrm{kN}-132 \mathrm{kN})$, until the steel reinforcement starts to yield. The fourth part represents the yielding of the reinforcement, up to the final failure of the beam.

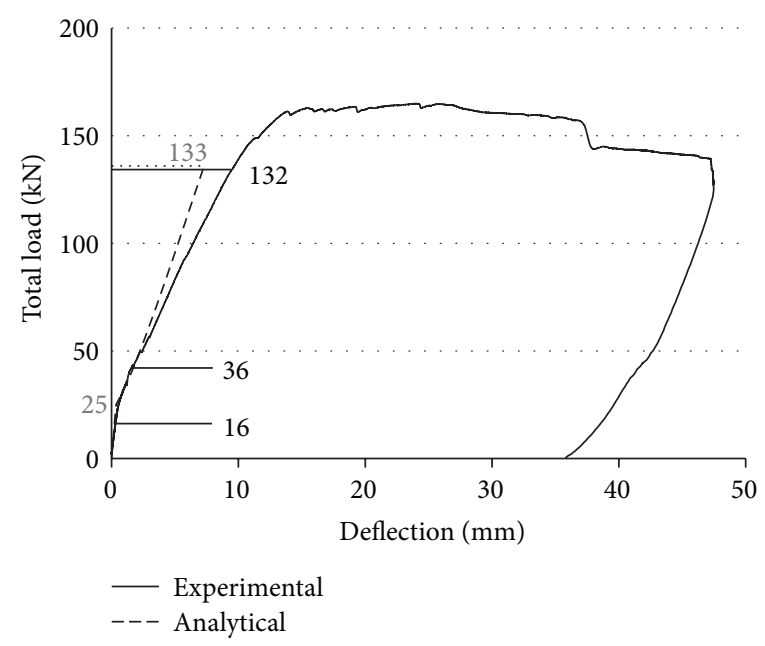

FIGURE 4: Analytical and experimental load-deflection curves of fully steel reinforced beam.

The calculated and experimental curves of the fully steel reinforced beam show good correspondence. In particular, good agreement exists between the theoretical and experimental loads at which the steel reinforcement starts to yield (analytically calculated at $133 \mathrm{kN}$ and experimentally observed at the end of the second linear zone, at a load of $132 \mathrm{kN}$ ) as well as between the theoretical and experimental cracking moments (analytically calculated at $25 \mathrm{kN}$ and experimentally observed in the second part of the curve, between $16 \mathrm{kN}$ and $36 \mathrm{kN}$ ).

5.1.2. Composite Beam with Longitudinal Steel Reinforcement and HPFRCC IPC Formwork as Shear Reinforcement. In the load bearing behaviour of the HPFRCC shear reinforced beam (Figure 5), the same 4 zones (1st linear elastic zone, concrete cracking, 2nd linear zone and steel yielding) can be distinguished as with the referential beam. In Figure 5, the calculated load at the cracking moment $(20 \mathrm{kN})$ is lower in comparison with the reference beam $(25 \mathrm{kN})$ because of the differences in concrete properties between both beams; a difference of $0.5 \mathrm{MPa}$ in the modulus of rupture results in a difference of $5 \mathrm{kN}$ in the load at which cracking initiates.

5.1.3. Composite versus Steel Shear Reinforced Beam. Even though the load-deflection curves of the HPFRCC IPC shear reinforced beam and of the referential beam show similar tendency with each other and with the theoretically predicted curves (Figures 5 and 6), important differences can be noticed.

As Figures 5 and 6 show, the experimental curve of the composite beam starts to deviate significantly from the analytical and referential load-deflection curves when the calculated, respectively referential, cracking moment is reached ((1) in Figure 6). The cracking moment is defined as the start of the deviation from the initially linear loaddeflection behaviour. Due to the presence of the external reinforcement, the load-deflection curve of the composite 


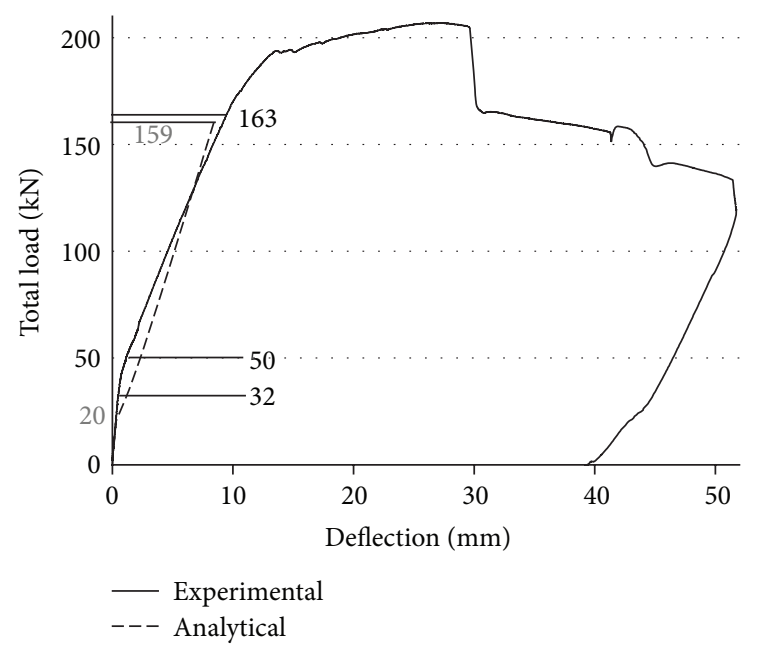

FIGURE 5: Analytical and experimental load-deflection curves of composite beam with longitudinal steel reinforcement and HPFRCC IPC formwork as shear reinforcement.

beam continues with the same slope even after the analytical and the referential cracking moments were reached. When the composite beam reaches its cracking moment $((2)$ in Figure 6) the load $(40 \mathrm{kN})$ is approximately twice as high as the calculated one $(20 \mathrm{kN})$ and as the one of the referential beam $(25 \mathrm{kN})$. This raise in cracking moment causes an upward shift of the second part of the curve, resulting in a lower deflection for the same total load ((3) in Figure 6). This shift may be useful in cases where the serviceability limit state of deflection is governing.

Another stage in the load bearing behaviour that is clearly influenced by the presence of the external HPFRCC IPC reinforcement is the initiation of the yield of the steel reinforcement. The start of the yielding behaviour of the composite beam corresponds well to the calculated value (at $160 \mathrm{kN},(4)$ in Figure 6) but does not correspond to the referential beam (at $132 \mathrm{kN}$, (5) in Figure 6). This difference can be attributed to the contribution of the external HPFRCC IPC reinforcement to the bending resistance of the beam. This effect is initially not taken into account in the composite beam design because the thickness of this external reinforcement is determined to meet the needs in shear, while the longitudinal reinforcement of 2 bars with a diameter of $16 \mathrm{~mm}$ is already fixed. Even during the steel yielding the contribution of the HPFRCC IPC can be noticed: instead of having a constant load during yielding like the referential beam, the loaddeflection curve tends to increase ((6) in Figure 6).

At a total load of $207 \mathrm{kN}$ (corresponding to a deflection of $30 \mathrm{~mm}$ ), the load-deflection curve of the composite beam shows a sudden drop ((7) in Figure 6): at this point the external HPFRCC IPC reinforcement fails in tension in the central part of the beam. As there are no shear forces in the middle third of the beam, the HPFRCC IPC contributes only to the bending resistance in this area. The drop has a magnitude of more or less $40 \mathrm{kN}$, whereas using the material properties discussed in Section 4.2 the contribution of the bottom part

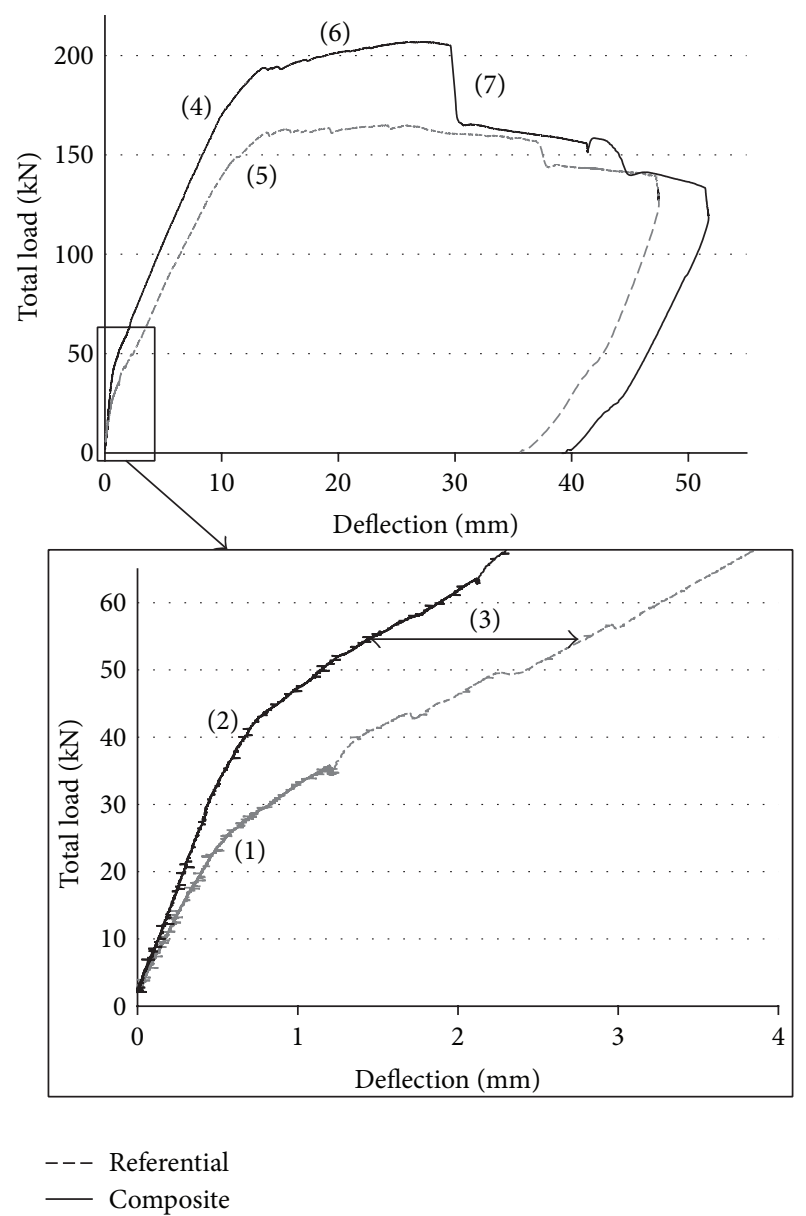

FIGURE 6: Comparison of the experimental load-deflection curves of fully steel reinforced beam and composite beam.

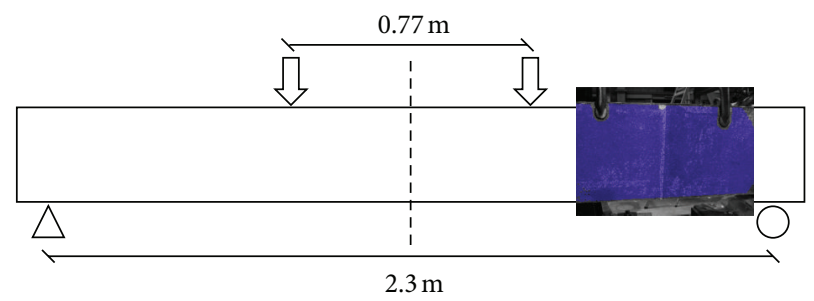

FIGURE 7: Location of the zone on the beam observed for crack evolution analysis.

of the HPFRCC IPC $U$-shape is calculated to be only $14,2 \mathrm{kN}$. Based on [24] the contribution of both upstanding sides of the $U$-shaped HPFRCC IPC can be estimated on $9,3 \mathrm{kN}$. Taking both bottom and side contributions into account the total magnitude of the drop still cannot be explained. This means that the presence of the HPFRCC IPC cover triggers other phenomena and causes changes in the behaviour of the subcomponents of the composite beam. After this failure of the HPFRCC IPC cover, the load-deflection curve of the composite beam is very similar to the curve of the reference beam. 


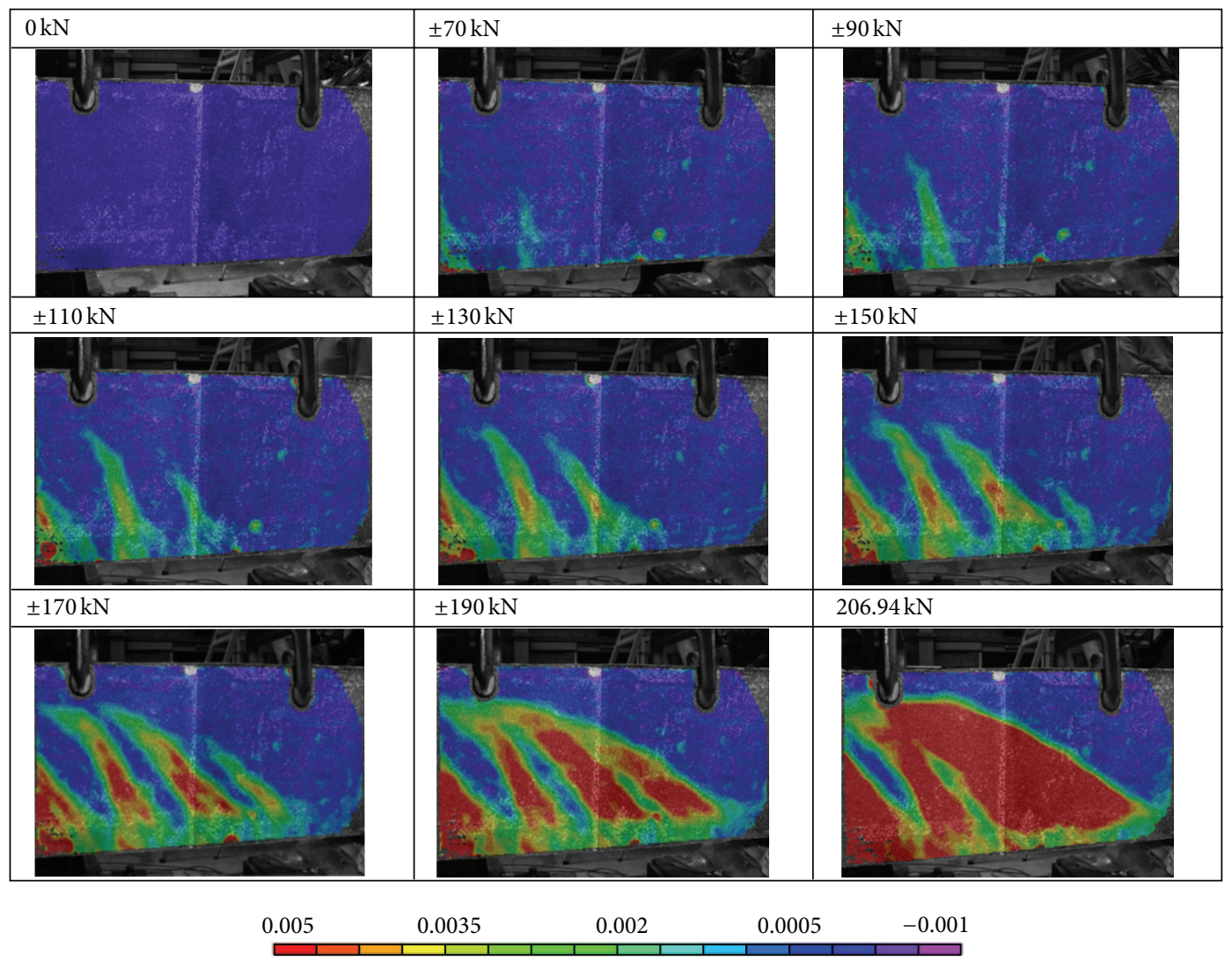

FIGURE 8: Fracture evolution composite beam.

5.2. Cracking Evolution of the Composite Beam. The phenomena described previously in Section 5.1 are further investigated by analyzing the fracture evolution of the composite beam. To study this fracture evolution the technique of digital image correlation (DIC) [22] is used, which is a noncontacting optical measurement technique. Displacements and consequently strains can be measured by the comparison of subsequent surface pictures taken from a speckle pattern of black spots on a white background, which is applied on the composite beam. Figure 8 shows the crack evolution in one of the shear zones, located as indicated in Figure 7. These images represent the strains, going from blue/purple where the strain is almost zero to red for the highest strains (going until 0,005). As the strain is the highest in the zones where cracks occur, these cracks can be visualized by the red parts of these images. It has to be remarked that by the nature of the measurement technique only the surface properties are measured, meaning that only the surface strains of the HPFRCC IPC cover are visualized and not the properties of the concrete underneath.

Before loading, the zero strain field corresponds to a completely blue image. The first difference in colour occurs at $70 \mathrm{kN}$, indicating the start of the crack formation. The next load steps show the crack evolution that will result in a failure of the beam due to shear crack growth through the total height of the beam. As these DIC images show, the strains are spread over a relatively wide area and not just localized at the underlying concrete crack line. This indicates the crack bridging capacity of the external reinforcement. Since this effect will also occur at the bottom surface of the concrete in the central bending zone, this may explain the increase of the cracking moment as observed in Figures 5 and 6. Further research on this topic is however needed to confirm these observations.

\section{A Retrospect on the Calculation}

Given the fact that some assumptions were made concerning the ultimate strain and the fibre efficiency of the HPFRCC IPC, as discussed in Section 3 and given the fact that the initial calculated amount of fibre layers is doubled for the experimental analyses, as discussed in Section 4.2.1, it is useful to reconsider the calculations. In Section 5.1.2 the effects of the increased number of fibre layers on the longitudinal reinforcement are taken directly into account, so only the shear calculation has to be reconsidered.

Back-calculating the necessary thickness of the shear reinforcement, as described in Section 3, but using the experimentally achieved maximum total load for the composite beam $(206.94 \mathrm{kN})$, and taking into account the effect of the contribution of the HPFRCC IPC to longitudinal reinforcement in the truss analogy, results in a HPFRCC IPC thickness of $2,1 \mathrm{~mm}$. This calculated thickness, where no reduction of $\varepsilon_{\mathrm{fu}}$ is applied, approaches very well the real thickness of 
around $2 \mathrm{~mm}$. This indicates on one hand that a reduction of the ultimate strain to the effective strain is not necessary and on the other hand that the calculation method described in de the fib bulletin 14 [19], based on Eurocode 2 [17], can be applied without any major changes for the calculation of a formwork made of HPFRCC IPC. This also confirms the assumption, based on [20], of the fibre efficiency of $1 / 3$ for the randomly in plane oriented chopped strand glass fibre mats.

\section{Conclusions}

The bending experiments described in this paper compare a fully steel reinforced concrete beam to a composite beam with equivalent shear reinforcement in glass fibre reinforced IPC. They demonstrate the following.

(i) Both beams show similar load-deflection behaviour, which means that the technique of TRC formwork as shear reinforcement actually works.

(ii) An advantage of the TRC formwork over traditional shear reinforcement is that it increases the cracking moment and load bearing capacity of the concrete beam.

(iii) The experiments indicate that the cracking moment of the concrete is delayed due to the presence of an external composite reinforcement, which is beneficial for cases where the serviceability limit state of deflection is dominant. Further research on this topic should confirm this hypothesis.

(iv) The thickness of this formwork to act as reinforcement can be calculated using the techniques of externally bonded reinforcement, where the effective strain can be taken equal to the ultimate strain.

(v) The necessary thickness of glass fibre reinforced IPC to be equivalent to steel stirrup, is quite small (order of magnitude millimetres).

As these findings show, stay-in-place formwork in glass fibre reinforced IPC offers a good alternative to the traditional steel stirrup reinforcement in concrete beams.

\section{Acknowledgments}

The research is partially funded by a Ph.D grant of the Institute for the Promotion of Innovation through Science and Technology in Flanders (IWT-Vlaanderen) for the first author. The authors gratefully acknowledge the support of the EU FP6 program Contex-T through the delivery of the glass fibre mats.

\section{References}

[1] J. E. Hall and J. T. Mottram, "Combined FRP reinforcement and permanent formwork for concrete members," Journal of Composites for Construction, vol. 2, no. 2, pp. 78-86, 1998.

[2] N. Deskovic, T. C. Triantafillou, and U. Meier, "Innovative design of FRP combined with concrete: short-term behavior," Journal of Structural Engineering, vol. 121, no. 7, pp. 1069-1078, 1995.
[3] I. C. Papantoniou and C. G. Papanicolaou, "Textile reinforced concrete (TRC) for precast stay-in-place formwork elements," in Tailor Made Concrete Structures, pp. 475-481, Taylor \& Francis, London, UK, 2008.

[4] C. G. Papanicolaou and I. C. Papantoniou, "Mechanical behavior of textile reinforced concrete (TRC)/concrete composite elements," Journal of Advanced Concrete Technology, vol. 8, no. 1, pp. 35-47, 2010.

[5] L. Ombres, "Flexural analysis of reinforced concrete beams strengthened with a cement based high strength composite material," Composite Structures, vol. 94, pp. 143-155, 2011.

[6] R. Contamine, A. Si Larbi, and P. Hamelin, "Identifying the contributing mechanisms of textile reinforced concrete (TRC) in the case of shear repairing damaged and reinforced concrete beams," Engineering Structures, vol. 46, pp. 447-458, 2013.

[7] A. Si Larbi, R. Contamine, E. Ferrier, and P. Hamelin, "Shear strengthening of RC beams with textile reinforced concrete (TRC) plate," Construction and Building Materials, vol. 24, no. 10, pp. 1928-1936, 2010.

[8] A. Si Larbi, R. Contamine, and P. Hamelin, "TRC and hybrid solutions for repairing and/or strengthening reinforced concrete beams," Engineering Structures, vol. 45, pp. 12-20, 2012.

[9] T. C. Triantafillou and C. G. Papanicolaou, "Shear strengthening of reinforced concrete members with textile reinforced mortar (TRM) jackets," Materials and Structures, vol. 39, no. 285, pp. 93-103, 2006.

[10] V. C. Li, "Invited paper on engineered cementitious composites (ECC), a review of the material and its applications," Journal of Advanced Concrete Technology, vol. 1, no. 3, pp. 215-230, 2003.

[11] O. Remy and J. Wastiels, "Development of impregnation technique for glass fibre mats to process textile reinforced cementitious composites," Plastics, Rubber and Composites, vol. 39, no. 3-5, pp. 195-199, 2010.

[12] H. Cuypers and J. Wastiels, "Thin and strong concrete composites with glass textile reinforcement: modeling the tensile response," ACI Special Publication Textile-Reinforced Concrete, SP-250, American Concrete Institute, 2008.

[13] J. Orlowsky, M. Raupach, H. Cuypers, and J. Wastiels, "Durability modelling of glass fibre reinforcement in cementitious environment," Materials and Structures, vol. 38, no. 276, pp. 155162, 2005.

[14] European Patent Office, "Inorganic resin compositions, their preparation and use thereof," EP 0861216 B1, May 2000.

[15] H. Cuypers, Analysis and design of sandwich panels with brittle matrix composite faces for building applications [M.S. thesis], Vrije Universiteit Brussel, Faculty of Engineering Sciences, 2002.

[16] E. A. Naaman and H. W. Reinhardt, "Setting the stage: toward performance based classifi-cation of FRC composites," in Proceedings of the 4th International Workshop on High Performance Fiber Reinforced Cement Composites (HPFRCC '03), pp. 1-4, June 2003.

[17] Comité Européen de Normalisation, "Eurocode 2: Design of concrete structures-Part 1-1: General rules and rules for buildings," ENV 1992-1-1, 2004.

[18] S. Verbruggen, Analysis and feasibility study of lost formwork for supporting concrete structures made from IPC [M.S. thesis], VUB, 2009.

[19] CEB-FIP, "fib bulletin 14 Externally bonded FRP reinforcement for RC structures," July 2008, http://www.fib-international.org/. 
[20] A. Bentur and S. Mindess, Fibre Reinforced Cementitious Composites, Taylor \& Francis, 2nd edition, 2007.

[21] http://www.ecc-belgium.be/nl/home/.

[22] M. A. Sutton, J. J. Orteu, and H. W. Schreier, Image Correlation for Shape, Motion and Deformation Measurements. Basic Concepts, Theory and Applications, Springer Science+Business Media, New York, NY, USA, 2009.

[23] ASTM International, "ASTM Standard C30, ASTM D2344/D2344M-00(2006) Standard Test Method for ShortBeam Strength of Polymer Matrix Composite Materials and Their Laminates," 2006, http://www.astm.org/.

[24] J. Blom, H. Cuypers, P. Van Itterbeeck, and J. Wastiels, "Modeling the behavior of textile reinforced cementitious composites under bending," in Proceedings of the 4th International Conference on Fiber Concrete, pp. 205-210, Prague, Czech Republic, 2007. 

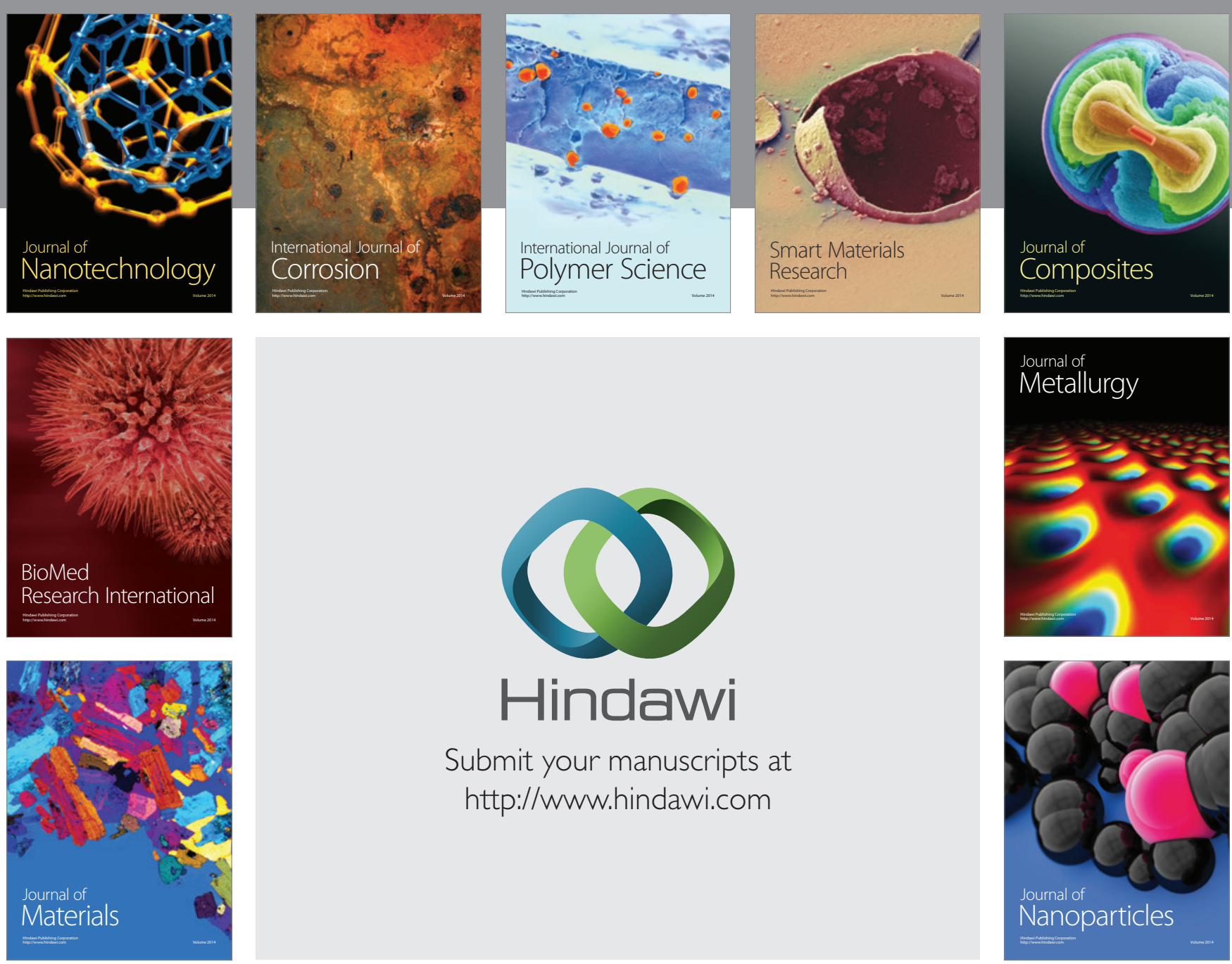

Submit your manuscripts at http://www.hindawi.com
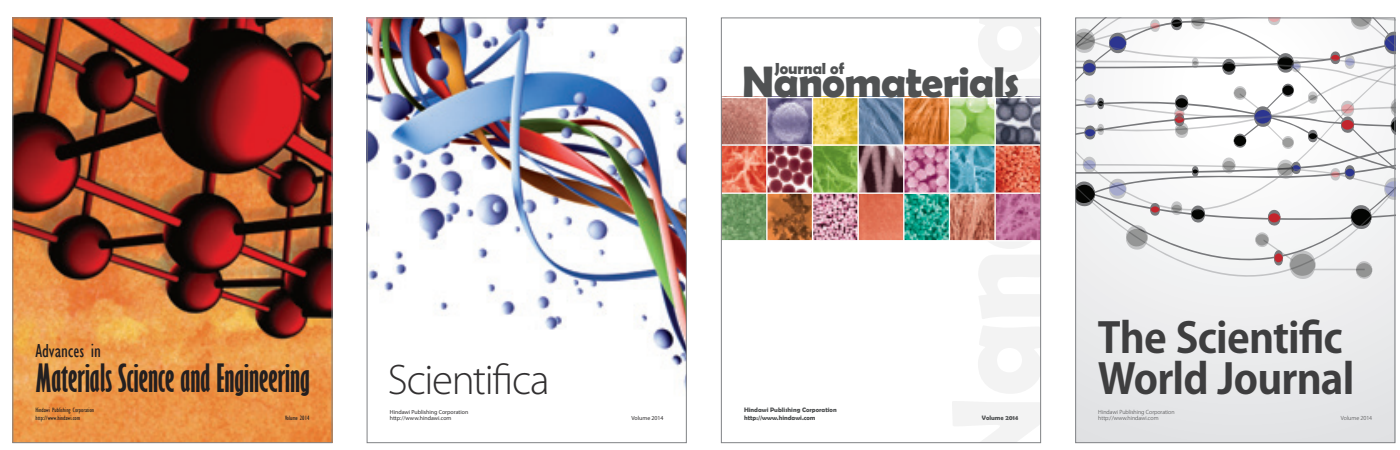

\section{The Scientific World Journal}
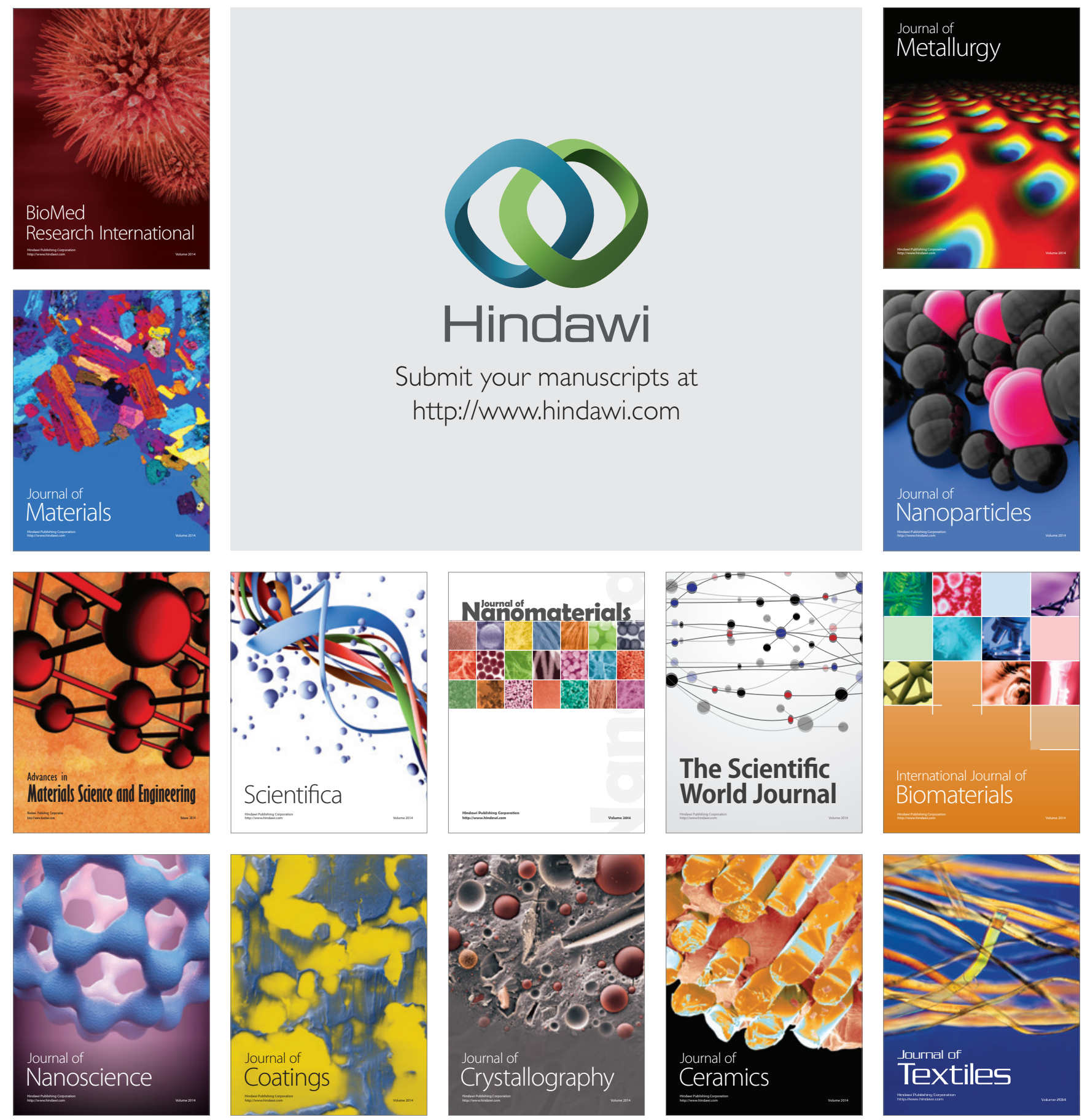